\title{
Force cancellation*
}

François Recanati

Synthese 196 : 4 (2019) p. 1403-1424

\section{The unity of the proposition: Hanks vs Soames}

If I assert that John is bald, the content of my assertion is the singular proposition that John is bald. That proposition can be represented as a structured entity having John and baldness as constituents, but it is clearly more than a list or aggregate of constituents - it can be true or false. What is it that makes a truth-evaluable proposition out of an object and a property? That is the problem of the 'unity of the proposition', which worried the founders of analytic philosophy and is widely considered as still in need of a solution. ${ }^{1}$

In his work over the last few years Peter Hanks has argued that what provides the 'glue' tying together the constituents of the proposition is the act of assertion (or some other speech act, in the case of nondeclarative utterances): the fact that, in saying that John is bald, I ascribe baldness to John or assert baldness of him. ${ }^{2}$ To be sure, propositional content and assertive force are standardly treated as two separate and orthogonal dimensions (Recanati

\footnotetext{
* The research leading to this paper has received support from the French Agence Nationale de la Recherche under grant agreement $\mathrm{n}^{\circ}$ ANR-10-LABX-0087 IEC and grant agreement $\mathrm{n}^{\circ}$
} ANR-10-IDEX-0001-02 PSL. I am grateful to Peter Hanks, Indrek Reiland, and several anonymous reviewers for discussion.

${ }^{1}$ See Gibson 2004, King 2007, Gaskin 2008, Soames 2010, Collins 2011, King, Soames and Speaks (2014) and Hanks 2015, among recent books directly bearing on the topic.

${ }^{2}$ See Hanks 2007, 2011, 2015. Hanks uses 'predication' for the act of (assertively) ascribing the property to the object, but that term is used by Soames in the 'noncommittal' sense, so I avoid it. (Reiland 2013, quoted below, uses 'predication*' for Hanks's notion and 'predication\#' for Soames's notion.) My use of 'assertion' instead of Hanks's 'predication' is objectionable, Reiland pointed out to me, because Hanks (2015: 161-66) explicitly distinguishes between predication as a multiple relation (between the subject, the property he or she ascribes, and the object to which s/he ascribes it) and assertion as a binary relation between the subject and a unitary proposition (construed itself as a type of act of predication); but that distinction seems to me somewhat artificial since to stand in the relevant 'tokening' relation to the type is to actually predicate the property of the object. 
2013). According to Hanks, however, the assertive force of my utterance is constitutive of its content because it is what secures the content's unity. Hanks concludes that

the content-force distinction should be abandoned altogether. I am skeptical of the idea that there are propositional contents that represent states of affairs independently of what speakers do in making assertions or forming judgments. An account has to be given of how these contents represent states of affairs that does not make any appeal to the intentional actions of speakers. I doubt that there is any way to do this. (Hanks $2007: 143)$

One might think there is an obvious objection to Hanks's approach, related to the reason why the force/content distinction was introduced in the first place. This is the so-called 'Frege-Geach point' (Frege 1918-26, Geach 1960, 1965). Were assertive force an aspect or part of the content of an indicative sentence, all the occurrences of the sentence expressing that content ought to have that force. But, for every indicative sentence, there can be occurrences of that sentence with assertive force and other occurrences without assertive force, while content remains unchanged. A proposition is unasserted when, for example, it is expressed by the antecedent of a conditional. Were it not for that fact that the same content can occur 'now asserted and now unasserted' (as Geach puts it), modus ponens would be invalid. ${ }^{3}$ It follows that assertive force is not - cannot be - part of content : content and force simply do not mix.

Appearances notwithstanding, one can accept the Frege-Geach point, and a strict content/force distinction, while retaining a solution to the problem of the unity of the proposition of the sort Hanks provides. One can maintain that what provides the 'glue' is an 'intentional action of the speaker', as Hanks puts it, provided the act in question is itself neutral with regard to the issue of illocutionary force. According to Soames, whose general view is otherwise very similar to Hanks's, what provides the glue is the act of (noncommittal) predication, which is performed whether the proposition is asserted or merely entertained

\footnotetext{
${ }^{3}$ I take Modus Ponens to be valid only if the sentence which occurs embedded in one premise (the conditional 'If P then Q') and unembedded in the other ('P') expresses the same content in both premises. If the assertive component is integral to content, then removing that component through embedding changes the content, and detaching the consequent becomes an illicit move (tantamount to the transition from 'If $P$ then $Q$ ' and 'R' to 'Q').
} 
(Soames 2010, 2012, 2014a, 2015). Entertaining the proposition that $a$ is $F$ is, for Soames, thinking of $a$ and predicating $F$-ness of it. Predication is noncommittal in the sense that the proposition thus entertained may or may not be assertively endorsed by the entertaining subject. On this view assertion, or judgment, involves two distinct acts: predication, and endorsement. What is common to asserted and unasserted occurrences of a given content is the (force-neutral) act of predication which is constitutive of that content. Predication thus understood is force-neutral and can only be made forceful through the additional act of endorsement. Using the act of predication in that sense (rather than the act of assertion) to unify the proposition is compatible with a strict force/content distinction, so the Frege-Geach problem does not arise in Soames's framework.

One problem with Soames's view is that it is mysterious what exactly predication is. To predicate a property of an object, on this view, is not to ascribe it to the object - for that would take us back to the notion of assertion and to Hanks's theory. So what is it? That question needs an answer. ${ }^{4}$ One cannot simply characterize 'predication' as whatever ties the object and the property together - for that would deprive the approach of any explanatory power.

I will discuss Soames's theory in a section 4. For the time being, I would like to focus on Hanks's own response to the Frege-Geach challenge. Hanks denies a premise in the FregeGeach argument : 'Were assertive force an aspect or part of the content, all the occurrences of the sentence expressing that content ought to have that force'. Hanks admits that some occurrences are deprived of assertive force, but offers an alternative explanation for that fact, compatible with his rejection of the content/force distinction. He argues as follows: the reason why there can be forceless occurrences of sentences expressing a given content is not that force is not part of content (the Frege-Geach explanation), but that there are cancelling devices such that when a content (with a force ingredient) is expressed by a sentence occurring in the scope of the device, the force ingredient is cancelled :

Frege's main reason for adopting the content-force distinction - the fact that we do not assert the antecedent or the consequent in an utterance of a conditional - is

\footnotetext{
4 'Although it is unclear that an informative answer can be given to this question', Soames writes, 'it is equally unclear that this is anything to worry about. Some logical and semantic notions - like negation - are primitive. Since this elementary point does not provoke handwringing, it is hard to see why the primitiveness of predication should' (Soames $2010: 29$ ).
} 
consistent with thinking that an assertoric element is included in the contents of declarative sentences. Frege's reaction to this fact about conditionals was to hold that the contents of declarative sentences are devoid of any assertive element, but this is not the only reaction one might have. An alternative is to hold that in certain contexts, for example, when a sentence is used inside a conditional, the assertive element is cancelled by the presence of the conditional. (Hanks 2011: 15)

It is interesting to note that the cancellation idea appears in Geach's own writings. In the preface to the 1971 edition of Mental Acts, he writes that 'a thought is by nature assertoric', 5 but can be 'inhibited from being so' if it occurs in certain contexts (Geach 1971 : xi).

\section{Reiland's dilemma}

Indrek Reiland (2013) objects that Hanks's cancellation strategy is untenable, because it runs into a dilemma. There are two options, he says, depending on how we understand 'cancellation', but they both lead to disaster as far as Hanks's theory is concerned. ${ }^{6}$

First option : cancellation 'completely obliterates' the act of assertion it operates on, so that 'it is as if the previous act hadn't taken place' (Reiland $2013: 243$ ). Since the cancelled act of assertion is what ties together the propositional constituents, cancellation thus understood will dissolve the unity of the proposition allegedly brought about by the act of assertion. Clearly, this would make Hanks's theory unworkable. The theory will work only if the unity secured by the act of assertion survives cancellation of that act in embedded occurrences of the content-carrying sentence.

The second option is meant to satisfy the survival requirement. Reiland describes it as follows :

The second way to think about cancellation is to think that it obliterates a part of the

\footnotetext{
${ }^{5}$ Russell also seems to have held that thought is by nature assertoric. In the Principles of Mathematics he writes that 'In every proposition, (...) we may make an analysis into something asserted and something about which the assertion is made' (Russell $1903: 43$ ). Soames cites this passage, and rejects the formulation as confused (Soames $2010: 27-28$ ). In Hanks's framework, however, Russell's statement can be accepted as it is.

${ }^{6}$ The same objection can be found in Hom and Schwartz $2013: 20-22$.
} 
contribution of the previous act. For example, one could think that the cancellation of predication obliterates the forceful part and leaves intact the part that does the tying. The problem with this is that it requires us to think of predication as having these separate parts. And then it seems that one of the parts, the one that does the tying, looks like predicating\# or non-committal property ascription. However, once we accept this we lose all sense in which judgments are the primitive propositional acts because now it seems that they consist partly of entertainings. This is Soames's approach. (Reiland $2013: 243$ )

To sum up, one way of understanding cancellation makes Hanks's theory unworkable, while the other one leads back to Soames's theory (neutral predication + endorsement). That's the dilemma.

Actually, there is a dilemma only if one adds a further premise - a premise which Reiland makes explicit and which we may dub the exhaustivity assumption :

Although Hanks doesn't really say much about cancellation, it seems to me that there are only two possible ways of thinking about it. (Reiland 2013 : 242, emphasis mine)

If we get rid of the exhaustivity assumption, the dilemma dissolves. The obvious thing to do, then, is to get rid of that assumption and start searching for a third way of thinking about cancellation. We already know a good deal about what a 'way of thinking about cancellation' must be like to be compatible with Hanks's theory. Cancellation must be understood in such a way that (i) the survival requirement is satisfied, which means that force cancellation must be partial, as in Reiland's second option : it must not cancel what does the tying (on pain of dissolving the tie). At the same time, (ii) the uncancelled part - the part that does the tying - must not reduce to a force-neutral act of noncommittal predication (on pain of giving up the project and accepting Soames's less ambitious theory). In the next section of this paper, I show that these requirements can be satisfied if we help ourselves to speech-act theoretic tools that have been available for more than thirty years.

\section{Three distinctions}

Let us start by noting an ambiguity in the notion of 'force', and in the assertion sign which is standardly used to distinguish forceful and forceless occurrences of indicative sentences 
carrying a given content. As R.M. Hare argued in his 1950 dissertation, and again in his article 'Meaning and Speech Acts' (published twenty years later), the assertion sign has two distinct functions. Its first function is that of a 'tropic', i.e. a mood indicator ; it tells the difference betwen e.g. a declarative utterance and an imperative utterance. (For imperative and interrogative utterances Reichenbach introduced special signs, ' !' and '?', on a par with the assertion sign). ${ }^{7}$ The second function is that of a 'neustic'. The neustic indicates the speaker's 'subscription' to the proposition s/he expresses in a certain mood. When a sentence occurs within a conditional or a disjunction, the neustic has to be removed from the logical representation of the sentence because in such contexts it does not have the force of a serious assertion. I will henceforth use subscripts to distinguish force in the tropic sense (force f $_{t}$ and force in the neustic sense (force $\mathrm{n}_{\mathrm{n}}$ ). Declarative and imperative utterances are distinguished by their force $\mathrm{e}_{\mathrm{t}}$; but a declarative utterance may or may not carry the force $\mathrm{n}_{\mathrm{n}}$ of a serious assertion (and likewise for imperative utterances). So a declarative utterance has a force t wich is a constitutive aspect of its semantic content, yet it may lack force ${ }_{\mathrm{n}}$ while still carrying that content. Since there are these two notions of force, or these two aspects of the notion of force,

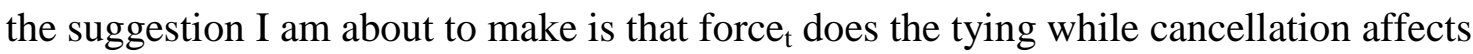
force $_{\mathrm{n}}$. In this way, both of the requirements mentioned at the end of section 2 can be satisfied. The cancellation induced by embedding is partial, as in Reiland's second option, but the 'part' that is unaffected by the cancellation is not forceless in the sense in which noncommittal predication understood à la Soames is forceless. Or so I am going to argue.

The second distinction we need is that which Austin (1975) introduced between locutionary and illocutionary acts. One may 'say that $p$ ' (locutionary act), or more generally utter an indicative sentence expressing the proposition that $p$, without actually performing the illocutionary act of seriously asserting that $p$. That will happen if the sentence which expresses that proposition is embedded in another sentence ; but that may happen also if the sentence is uttered in isolation, as in irony or displayed assertion (Recanati 1987 : 233-35, 2007, 2010 : chapter 6). I will focus on the unembedded cases for the time being. ${ }^{8}$ In Recanati 1987 : 263 I give the following example (due to Ducrot) :

\footnotetext{
${ }^{7}$ Reichenbach 1947 : 339-43 ; see also Dummett, who characterizes force as that part of the meaning of an sentence in virtue of which it is 'conventionally understood to express an assertion and not e.g. a command' (Dummett 1973 : 302).

${ }^{8}$ See sections 5 and 6 on the relation between force cancellation in embedded and unembedded cases.
} 
(1) A : You are an idiot

B : I am an idiot. That's very kind of you.

In this dialogue B's utterance 'I am an idiot' expresses the proposition that B is an idiot, so in making it B 'says that' he is an idiot (locutionary act), but this is not a bona fide assertion. B is merely echoing A's previous utterance. The same thing holds for free indirect speech, or for irony. In saying ironically 'John is a fine friend' after John has brutally betrayed me, I 'say that' he is a fine friend (locutionary act) but I don't subscribe to what I say.

In such cases, the force of a serious assertion is lacking, and what remains - the 'uncancelled' part — is the locutionary act and its content. Now what is a locutionary act exactly ? This is a difficult issue, but one thing is clear : the locutionary act is more than just the act of expressing a force-neutral proposition (what Searle 1969 calls a 'propositional act'). To report the locutionary act performed by uttering a sentence, Austin says, we use indirect speech : the locutionary act performed by means of the sentence 'The cat is on the mat' is described by Austin as the act of saying that the cat is on the mat, the locutionary act performed by uttering 'Get out' as the act of telling the addressee to get out, the locutionary act performed by uttering 'Is it in Oxford or Cambridge ?' as the act of asking whether it is in Oxford or Cambrige (Austin $1975: 95) .^{9}$ It is clear that in these reports, which are said to capture the locutionary content of the utterance, expressions like 'say that', 'tell to' and 'ask whether' track the mood of the uttered sentence. The locutionary content of an utterance in Austin's sense is therefore not a force-neutral proposition but includes a component corresponding to Hare's tropic (Recanati 1987 : 245-48, 2013).

In speech act theory, so-called 'sentence moods' (declarative / imperative / interrogative / exclamative...) indicate which type of illocutionary act the sentence is used to perform. But there is a difference between the illocutionary act whose performance is thus signaled and the illocutionary act (if any) which is actually performed. In irony, the act of assertion whose performance is signaled by the use of an indicative sentence is not actually performed, but mimicked or displayed (Clark and Gerrig 1984, Ducrot 1984 : 210-13). The

\footnotetext{
${ }^{9}$ These reports look very much like reports of (generic) illocutionary acts, and that is the main reason why Searle (1968) rejected Austin's locutionary/illocutionary distinction as illgrounded. In Recanati (1987 : chapter 9) I defend Austin's distinction against Searle's criticism.
} 
speaker 'makes as if' to assert (Grice 1989 : 30). Accordingly, in my early work (Recanati $1980,1987)$, I characterized the locutionary act as the act of conventionally indicating the performance of an illocutionary act (e.g. the illocutionary act of asserting that $p$ ). In performing a locutionary act one may, or may not, actually perform the illocutionary act thus indicated. On this view the notion of illocutionary act is primary - the locutionary act is characterized in terms of it (Recanati 2013). Still, there is a contrast between the locutionary act and the illocutionary act, corresponding to the distinction between the illocutionary act indicated and the illocutionary act actually performed. ${ }^{10}$

In the process of interpreting an utterance, the illocutionary act whose performance is signaled has to be fleshed out in context. This involves :

(i) specifying its propositional content by contextually assigning values to indexicals and free variables (saturation), by assigning contextually specific senses to the lexical items (modulation), etc. (See Recanati 2004)

(ii) contextually specifying a particular illocutionary force compatible with the sentence's illocutionary potential (corresponding to its mood) (See Austin 1975)

(iii) filling in the various parameters for the context in which the illocutionary act indicated is supposed to take place.

The last bit is especially important : it is the key to properly understanding force cancellation. To explain why, I must introduce the third of the three distinctions I announced.

The third distinction is a distinction between two contexts. The locutionary context is the context in which the locutionary act takes place. Its agent is the speaker, its time is the time of speech, its world is the actual world etc. ${ }^{11}$ The illocutionary context is the context of the illocutionary act whose performance is indicated. Its agent, time, world may, though of course they need not, differ from the agent, time and world of the locutionary context (Recanati 2007: 223-28, 2010 : 198-202 ; see also Schlenker 2004). With that distinction in hand, we can account for both serious assertion and displayed assertion (cases where the

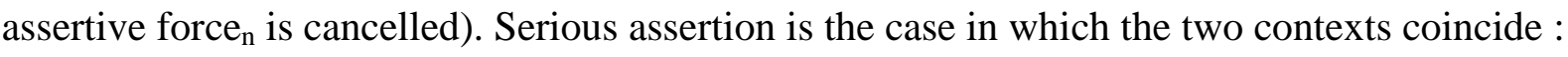
the illocutionary context is the locutionary context, that is to say, the act of assertion whose

\footnotetext{
${ }^{10}$ My notion of a locutionary act is similar to Barker's notion of a proto-illocutionary act (Barker 2004 : 45ff).

${ }^{11}$ The locutionary context roughly corresponds to Kaplan's notion of context.
} 
performance is conventionally indicated is performed by the speaker in the actual context of speech. In other cases, when the utterance lacks the force of a serious assertion, the illocutionary act indicated is understood as taking place in a context distinct from the locutionary context. In these cases, the speaker does not 'subscribe' to or 'endorse' what he or she says. Responsibility for the illocutionary act is displaced to some other agent, actual or potential, or to some other temporal slice of the same agent, in an echoic manner. ${ }^{12}$

Specifying the illocutionary context is part of the process of interpretation. In particular, one has to identify what Ducrot (1980a \& b, 1984) calls the 'enunciator', i.e. the person (or group of persons, possibly generic) who subscribe and take responsibility for the illocutionary act. In irony, that is the person one is ironically mocking ; in speech or thought reports, this is the person whose speech or thought one is reporting. In serious assertion, the enunciator is the speaker, but in many cases they will diverge. On this view force $\mathrm{n}_{\mathrm{n}}$ counts as 'cancelled' just in case the speaker, in the actual context (the locutionary context), does not perform the illocutionary act indicated, but implicitly or explicitly presents it as performed by some other agent in some other context.

In this framework an 'assertive' component remains even when the force of a serious

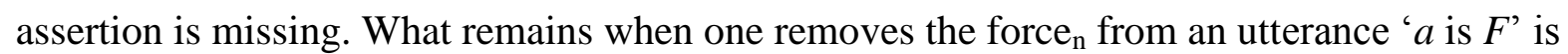
the illocutionary act indicated, an act in which the enunciator (possibly distinct from the speaker) ascribes the predicate $F$ to the subject $a$. The assertive component present in that act is sufficient to tie the propositional constituents together. Q.E.D.

Let me now repeat the passage from Reiland I quoted above, to see where he goes wrong:

One could think that the cancellation of predication obliterates the forceful part and leaves intact the part that does the tying. The problem with this is that it requires us to think of predication as having these separate parts. And then it seems that one of the parts, the one that does the tying, looks like predicating\# or non-committal property ascription. (...) This is Soames's approach.

\footnotetext{
${ }^{12}$ On echoicity, see Ducrot 1980a, 1980b, 1984, Sperber and Wilson 1981, 1986, Recanati 1987, 2000, 2007, 2010 : chapter 6, Wilson and Sperber 1992, 2012, Clark 1996 : chapter 12, Wilson 2000, 2006, Stokke 2013, and the papers in De Brabanter (ed.) 2005. The label 'echoic' comes from Sperber and Wilson (Ducrot talks of 'polyphony', Clark of 'staging', etc.).
} 
On the view I have put forward, there are indeed two 'separate parts', one of which does the tying while the other is affected by cancellation. They are separate in the sense that we can have one (force in the tropic sense) without the other (force in the neustic sense). The

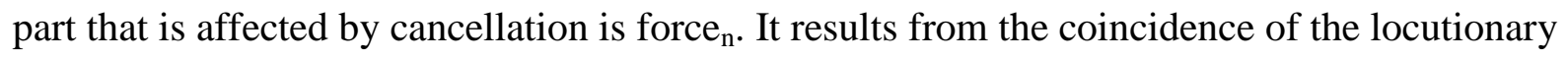
and illocutionary contexts : taking up the role of enunciator, the speaker assumes responsibility and subscribes to what is said. When there is no such coincidence, force $_{\mathrm{n}}$ is missing or 'cancelled', due to contextual factors. The other part - that which does the tying and survives cancellation - is locutionary content. But locutionary content is not force neutral, in the sense relevant to Soames. The locutionary content of an utterance is the illocutionary act whose performance it indicates. That illocutionary act - whether or not it is endorsed by the speaker - is what ties the object and the property together in the predication ' $a$ is $F$ '.

\section{Comparison with Soames and Hanks}

Any theory of content must account for the fact that there are two types of occurrences of indicative sentences expressing a given content: asserted and unasserted, or (to use Reiland's terminology) forceful and forceless. Two sorts of account are possible, depending on what is considered as basic (Table 1). According to Hanks, what is basic are the forceful occurrences. Thoughts are intrinsically assertive, but the assertive force that is constitutive of content can be cancelled or inhibited. Forceless occurrences are therefore considered as having derivative (i.e., nonbasic) status since they result from a supplementary operation of force cancellation. For Frege and Soames, in contrast, it is the forceful occurrences that are treated as derivative or nonbasic : they result from a supplementary operation, whereby the subject endorses the content which she entertains. Without that supplementary operation of endorsement a thought is forceless. 


\begin{tabular}{|l|l|l|}
\hline & Forceful occurrences & Forceless occurrences \\
\hline Hanks & $\begin{array}{l}\text { Basic (thoughts are } \\
\text { intrinsically assertive) }\end{array}$ & $\begin{array}{l}\text { Derivative (involve a } \\
\text { supplementary operation of } \\
\text { force cancellation) }\end{array}$ \\
\hline Soames & $\begin{array}{l}\text { Derivative (involve a } \\
\text { supplementary operation of } \\
\text { endorsement) }\end{array}$ & $\begin{array}{l}\text { Basic (thoughts are not } \\
\text { intrinsically assertive ; } \\
\text { thoughts per se are forceless) }\end{array}$ \\
\hline
\end{tabular}

Table 1 : Hanks vs Soames

In my framework, as in Hanks's, forceful occurrences (judgments/assertions) are treated as basic. Illocutionary acts come first. Language has evolved conventional ways of performing them, and these conventional forms can be exploited to 'stage' the performance of an illocutionary act which the speaker is not really performing. Force cancellation in such cases result from the speaker's distancing herself from the illocutionary act whose performance is indicated. (Force cancellation in embedding cases can be treated similarly, as we shall see in sections 5 and 6. Embedding can be analysed as triggering a divergence between the locutionary context and the illocutionary context for the embedded constituent. ${ }^{13}$ )

Hanks criticizes my account on the grounds that it maintains a strict force/content distinction and is therefore similar to the Frege/Soames approach. In my framework, indeed, a given locutionary content may be expressed without having force in the neustic sense without endorsement. But Hanks does not accept the Fregean idea of endorsement. He objects to my account that

[it] is like Frege's in positing a neutral, non-commital core inside every assertion.

Recanati calls the neutral core a locutionary act; for Frege it is an act of expressing a proposition. The neutral core amounts to a full-fledged assertion when it is accompanied by an extra, non-neutral act that boosts the total act to the making of an assertion. (Hanks 2015: 96n)

\footnotetext{
${ }^{13}$ This is another point of convergence with Barker, who claims that 'the semantic structure of logical compounds is essentially the same kind exhibited by... irony' (Barker 2004 : 89) : both 'involve a type of pretence' (Barker $2004: 89$ n).
} 
But this is a misinterpretation of my view. Endorsement, on my account, is not a separate act ('an extra, non-neutral act') or a supplementary operation. Endorsement simply means that the speaker is the enunciator (and more generally that the illocutionary context is identical to the locutionary context). That is the basic case - the 'forceful' case. Forceless occurrences do involve a supplementary operation : cancelling. Cancellation results from the fact that the speaker is staging the performance of an illocutionary act, rather than genuinely going through the performance. This falls under the broad concept of simulation. ${ }^{14}$ Forceless occurrences are derivative in the sense that they involve the simulation of the illocutionary acts that are performed in the basic cases.

For Soames, as we have seen, forceful cases such as assertion or judgment are nonbasic. They involve two distinct acts : entertaining, and endorsement. Soames holds that some attitudes consist of $a$ single act of the mind while others consist of two acts (Soames $2014 \mathrm{~b}$ : 00). ${ }^{15}$ For example, to deny a proposition is to perform two acts : entertaining the proposition, and rejecting it. Acts of judgments likewise consist of two acts : entertaining, and endorsing. Acts of judgment or denial are, for Soames, more complex than simple acts of

\footnotetext{
${ }^{14}$ Cosmides and Tooby (2000) speak of 'decoupling'. This term is borrowed from Leslie's theory of pretense (Leslie 1987), but Cosmides and Tooby insist that decoupling is a broader notion than pretense. Decoupling rests on 'the ability to act as if', an ability which underlies a
} diverse range of behaviours, including 'the many categories of actions undertaken under conditions of uncertainty (e.g., we will assume they got the message about the restaurant; or we will act as if there is a leopard hiding in the shadows of the tree), actions with respect to social conventions or deontic commitments (which are by themselves incapable of being either true or not true, at least in an ordinary sense; e.g., Elizabeth is the rightful Queen of England; it is praiseworthy to make the correct temple sacrifices), adapting oneself to the wishes of others, hypothesis testing, and so on. Pretense (Leslie 1987) and deception (Whiten \& Byrne, 1997) are simply extensions of this same competence, in which the agent knows the representations on which she is acting are false' (Cosmides and Tooby $2000: 64)$.

15 'Some [cognitive acts] — judging and asserting that o is red — involve further cognitive acts in addition to predicating redness of o, whereas others — seeing and imagining — do not. To judge or assert that o is red is to think of o as red and to do something else. In the case of judging, this something else is endorsing, in the sense of adopting that way of thinking — of o as red - as potential basis for further thought or action' (Soames 2014b: 228-29). 
entertaining. ${ }^{16}$ Such a simple act occurs, for example, when one imagines something. Imagining consists of a single act of entertainment, and so do, according to Soames, mental acts such as seeing and visualizing (Soames 2014b : 229).

I contest Soames's typology, on two grounds. First, I hold that seeing is inherently judgmental (forceful) and carries a primitive form of endorsement. That prima facie endorsement, as we may call it, can be overriden in context (see Fodor 1983 : 102ff on the fixation of belief). Second, I take the remaining acts mentioned by Soames, imagining and visualizing, to be obviously related : visualization is a (visual) form of imagination. Supposing is another, non phenomenal form of imagination. All these forms of imagination can be treated, following Husserl (1900-01) and especially Meinong (1902), as derivative and based on the simulation of some more basic state (such as judgment or visual perception). ${ }^{17}$ The more basic states are forceful, and the forceless cases result from the simulation operation which cancels the force of the simulated state. (When it comes to the imagination, the simulation approach has obvious advantages and is adopted by most theorists.)

I conclude that the distinction between cases with and without endorsement does not automatically force me into the camp of Frege and Soames. Contrary to what both Hanks ${ }^{18}$

\footnotetext{
${ }^{16}$ There are indications that Soames may be changing his mind on these matters. In the January 2014 manuscript version of his Hempel lectures of 2013, he wrote : 'judg[ing] or assert[ing] that $\mathrm{B}$ is red does involve doing something over and above predicating [redness of B]... In such cases we represent B as red, while taking a further stance towards our representational act. All events of judging B to be red involve predicating redness of B plus this further cognitive doing'. In the published version, this becomes : 'whether or not [judging or asserting that $\mathrm{B}$ is red] involves doing something distinct from and independent of predicating redness of $\mathrm{B}$, as opposed merely to predicating redness of $\mathrm{B}$ in a distinctive way, is less clear than one might think... I incline to the latter [option].' (Soames 2015 : 22-23 ; emphasis mine). Soames says he is not sure 'how much it matters what we say about this question' (2015:23), but I think a good deal of the present debate hinges on it.

${ }^{17}$ See e.g. Mulligan 2015 on the Husserl-Meinong view that imaginative states simulate more basic states. On this picture, the variety of simulated states accounts for the variety of forms of imagination.

${ }^{18}$ See his comment on an earlier version of this paper: 'The structure of your view looks like it preserves the structure of the Fregean view, and in that respect it is like Soames's account. By 'structure' I mean the two-component model of assertion. In an assertion there's a non-
} 
and two anonymous reviewers suggested, the difference between my view and Soames's (Table 2) is as sharp as the difference between Hanks's view and Soames's (Table 1).

\begin{tabular}{|l|l|l|}
\hline & Basic case & Supplementary operation \\
\hline Soames & Entertaining (forceless) & Endorsement \\
\hline Myself & Illocutionary act (forceful) & Force-cancelling simulation \\
\hline
\end{tabular}

Table 2 : My view compared with Soames's

The only difference I can see between me and Hanks is that I accept, while he rejects, the notion of endorsement. But I do not see how Hanks himself can account for the distinction between forceful and forceless cases without something like that notion. Hanks admits, indeed emphasizes, that acts of cancelled predication are 'neutral, in the sense that they do not commit the subject to the truth of her act of predication' (Hanks 2015 : 98). Now 'commit' seems to be in the same ballpark as 'subscribe' or 'endorse', so it is not clear what difference the terminology actually makes. Hanks thinks there is a substantial difference, however: while there is something objective about commitments, subscribing or endorsing are intentional acts of the subject. That difference matters because, according to Hanks, intentional acts of the subject are irrelevant when it comes to force cancellation. Hanks uses Frege's theatrical example to make this point. Theatrical contexts are, by convention, contexts in which force is cancelled. Endorsement or the lack of endorsement has no role to play, because

There is nothing the actor can do to make his lines in the play count as full-fledged assertions. No act of identification or subscription or endorsement can turn his stageutterances into real assertions. The only way for his utterances to count as genuine assertions is for the theatrical conventions to be lifted and the play to end. This drives home the fact that these conventions create a context that overrides the assertive character of the actor's utterances. No intentional actions on the part of the actor can

commital act (Fregean entertainment, Soamesian predication, locutionary act), which determines propositional content, and then on top of that there's a commital act, an act of endorsing or subscribing or something similar. I worry that if this structure is in place then we'll be able to reconstruct something that looks an awful lot like the content-force distinction.' (Hanks, personal communication, August 2013) 
restore that assertive character, at least not until the actor leaves the theatrical context (Hanks 2015 : 96n).

Hanks seems to suggest that there is nothing intentional in force cancellation, as if it was something occurring in virtue of brute conventions. This seems to me an indefensible position. To 'leave the theatrical context', it is sufficient for the actor on the stage to overtly manifest (and not merely simulate) the intention to speak seriously. The actor can say 'Fire ! Fire !' for example and manage to convince the audience that he is no longer acting. Similarly, to enter the theatrical context, it is sufficient to make one's intention to do so manifest to listeners willing to cooperate and participate in the game of make-believe. Contrary to Hanks's claim, the assertive or non-assertive character of an utterance is entirely a matter of 'intentional actions' on the part of the speaker. Whether or not conventions are involved, speaker's meaning is what determines whether there is endorsement or cancellation. It does so, on my account, by setting the parameters of the illocutionary context in relation to the locutionary context. Setting these parameters is a fundamental aspect of the overall interpretation of an utterance, an aspect which formal linguistics has recently started to investigate. $^{19}$

\section{Force cancellation and embedding (1)}

An issue arises concerning the relation between force cancellation in unembedded cases (i.e. cases of displayed assertion of the sort I have talked about so far) and the type of cancellation that occurs when a sentence is embedded in a complex construction ('P or Q', 'If $\mathrm{P}$ then Q', 'John believes that P'...). Cases of displayed assertion such as irony or free indirect speech involve a form of simulation or pretense of a kind which Clark claims is pervasive in natural discourse (Clark 1996 : 353-84, 2016). The force of the utterance is cancelled because the speaker is not seriously performing the indicated illocutionary act but merely simulating its performance. Can this account be extended to the force cancellation at stake in embedding cases? That is not obvious, but my suggestion is that we should try.

\footnotetext{
${ }^{19}$ I have in mind the studies of free indirect speech which implicitly or explicitly posit two distinct contexts (e.g. Doron 1991, Schlenker 2004, Sharvit 2008, Eckardt 2015).
} 
As a warmup, consider oratio obliqua reports such as 'John believes that $p$ ' or 'John said that $p$ '. As Quine and, later, simulation theorists ${ }^{20}$ emphasized, there is a 'dramatic' component in such reports :

In indirect quotation we project ourselves into what (...) we imagine the [subject's] state of mind to have been, and then we say what, in our language, is natural and relevant for us in the state of mind thus feigned (Quine $1960: 219$ )

In other words, the embedded sentence is evaluated with respect to the perspective of the ascribee, rather than with respect to the speaker's own perspective. ${ }^{21}$ The speaker takes responsibility for the top-level assertion (that John believes/said that $p$ ), but it is John who takes responsibility for the embedded assertion that $p$. That assertion is simulated by the speaker, putting herself in John's shoes. ${ }^{22}$

Leaving the special case of ascriptions aside, there are linguistic studies which show that certain connectives (e.g. French 'puisque' [= since] in 'P puisque Q') are 'polyphonic' in that they trigger a divergence between the speaker and the enunciator for the embedded constituent. In typical uses of ' $P$ puisque $Q$ ' it is the speaker's interlocutor who is presented as accepting that $\mathrm{Q}$, and from that premiss which his opponent accepts the speaker derives the conclusion that P (Ducrot 1980b : 47-49). Similarly, 'but' has been given a polyphonic

${ }^{20}$ See e.g. Davies and Stone (eds.) 1995.

${ }^{21}$ The displacement of perspective we find in oratio obliqua is limited : by and large, the indexicals in the embedded sentence are still interpreted with respect to the speaker's actual context (the locutionary context) ; that is part of what Quine means when he says that we say 'in our language' how things stand from the alien perspective we temporarily espouse. In oratio recta, arguably, both the illocutionary context and the locutionary context shift (Recanati 2010 : 202-4).

${ }^{22}$ In philosophy, the opacity phenomena characteristic of speech and attitude reports are standardly treated as involving a shift of perspective : substitution of equivalent expressions in the embedded portion of the report may fail to preserve truth if the expressions in question are not equivalent for the subject whose speech or thought we are reporting. In psychology, it has been shown that mastery of intensionality develops together with mastery of perspective shifts. Perspective-shifts in attitude sentences are also a fruitful area of investigation in linguistics. 
analysis which construes 'P but Q' as a crystallised argument between two protagonists, with the speaker idenfying with the second one (the enunciator of Q).

Admittedly, these are also special cases. Not all connectives are supposed to be 'polyphonic' in the sense in which 'puisque' is if Ducrot's description is correct. ${ }^{23}$ Now what we are after is a theory of embedding general enough to account for force cancellation as it occurs in embedding cases, whatever the embedding construction. To evaluate the prospects for such a theory, we should look at the standard connectives : 'and', 'or', 'not', 'if... then', etc. How are we to account for force cancellation in constructions such as 'P and Q', 'P or Q', 'Not P', 'If P then Q'?

Conjunction is interesting, because it is not obvious that in conjunctive environments the assertive force of the conjuncts is actually cancelled. It is prima facie unclear whether or not the speaker who asserts 'P and Q' asserts that $\mathrm{P}$ and asserts that $\mathrm{Q}$. Is $\mathrm{P}$ literally asserted, or is it merely an (obvious) consequence of something that is literally asserted ? The answer depends on one's theory. In the current framework, there is no particular reason to deny that ' $\mathrm{P}$ ' and ' $\mathrm{Q}$ ' are individually asserted by the speaker who asserts their conjunction, as they seem to be. That is the position Hanks naturally takes :

In the assertion of a conjunction a speaker does assert each conjunct. Conjunction is unlike disjunction in this respect. An obvious way to explain this difference is to say that 'or' cancels assertion but 'and' does not. Uses of 'or' create cancellation contexts ; uses of 'and' do not. This would explain why we do not assert disjuncts but we do assert conjuncts. (Hanks $2015: 103$ )

On this view, embedding does not automatically cancel force, but cancels force in some cases and not others. In support of such a theory, we note that, in French, there are instances of indicative conditionals in which the force of neither antecedent nor consequent seems to be cancelled. ${ }^{24}$ In contrast to the case of conjunction, however, 'if... then...' normally cancels

\footnotetext{
${ }^{23}$ Indeed French 'puisque' [since] contrasts with French 'car' [for]. 'Car' is not polyphonic and, for that reason, cannot be substitute for 'puisque' in certain contexts (Ducrot 1980b : 4748).

${ }^{24}$ Such instances are discussed by Ducrot 1972: 175-79 and by Cornulier 1985 : 60-77 (under the heading of 'bi-assertive conditionals'). Example : 'Si la vie et la mort de Socrate sont d'un sage, la vie et la mort de Jésus sont d'un Dieu' (Rousseau). The phenomenon is less common
} 
the force of the antecedent and consequent. The special case in which conditionals do not cancel force arises (in French) when the antecedent is presupposed as part of the commoun ground : then, and only then, is the consequent actually asserted by the speaker who asserts the conditional.

What about the standard (force-cancelling) uses of conditionals? Many theorists have emphasized the (obvious) connection between the protasis in a conditional 'If P then Q' and the act of supposing that $P$. If we treat supposition as a form of imagination, and imagination as a simulative state, it becomes very natural to say that the speaker (or thinker) simulates a committal attitude toward the antecedent, and that the consequent is asserted within that simulation, that is, under the pretense that the antecedent holds. On this analysis, the simulative assertion of the consequent in a conditional is similar to the (unembedded) simulation of assertions under suppositions in natural deduction. ${ }^{25}$ The analysis, by itself, does not take a stand on the further issues of whether conditionals have truth-conditions and what (if anything) those truth-conditions are. The important point is that, whenever the speaker simulates a forceful act which she does not actually perform, there is a difference between the context in which the simulation takes place and the context in which the act that is the target of simulation is supposed to take place. In the case of conditionals, for example, there is a difference between the world of the illocutionary context, viz. the imaginary world of the pretense, and the world of the locutionary context, viz. the actual world (or, more generally, what Fauconnier $1985: 17-18$ calls the 'parent' world).

In the framework I am sketching, the connectives at best constrain, but do not determine, the way the illocutionary parameters are set in context. Moreover, the constraints

in English, but still exists, as witnessed by the following sentence from Antonia Fraser's foreword to Love and Louis XIV : 'But if gallantry is one of my themes, then religion is another.' A related phenomenon is the non-cancelling use of modals, as in 'Obama may be the President, he is far from having all the powers' : here the force of 'Obama is the President' is not cancelled even though the sentence is embedded under a possibility modal. (I am indebted to Adèle Mercier for pointing out the analogy between the two types of case, and for providing the Fraser example.)

${ }^{25}$ There is an important difference between the two cases - a difference which simulation accounts of conditionals tend to underplay (see Recanati 2000 : 51-58). Here, however, I am only concerned with the commonalities, which simulation accounts of conditionals do capture. 
on parameter setting carried by the connectives may be thinner or richer, depending on the connective. With disjunction, the constraint seems rather light. What is the illocutionary context for the disjuncts in a disjunction? Who is the enunciator? It's admittedly hard to come up with a general story, but there is an easy way out : we may construe the enunciator as generic in such cases. On this view, the illocutionary act indicated by each disjunct is the act (type) one would perform by uttering that disjunct in isolation. These acts indicated by the disjuncts serve as arguments to the disjunction relation, as in Hanks's theory. So there is no need to argue, with Hanks, that the force cancelling power of embedding is a brute conventional fact. Using generic enunciators, we can extend the account of force cancellation that works for simulation cases to all cases of force-cancelling embedding. The resulting theory has the power to account for the fine-grained 'readings' which arise in context when the illocutionary parameters are assigned determinate values. Such readings correspond to the variegated uses of 'and', of 'or', and of 'if' registered in dictionaries (Cornulier 1985 : chapter 1). The multiplicity of these readings or uses is compatible with a unified theory involving contextual parameters.

\section{Force cancellation and embedding (2)}

The appeal to generic enunciators (and, more generally, generic illocutionary contexts) weakens the theory somewhat, since it is arguably a stipulative move. But that move is necessary if we want a single theory to encompass both types of force-cancellation : that which is based on simulation and that which is due to embedding. By using generic contexts, we can extend the scope of the theory so as to encompass recalcitrant cases in which no particular illocutionary context is made salient in the discourse situation. Without generic contexts, we would have to acknowledge that there are cases of force-cancellation due to embedding which do not involve the kind of simulation at work in instances of displayed assertion such as irony or free indirect speech. I will illustrate this dilemma with the case of negation.

There is a long tradition of giving negation what we may describe with hindsight as a 'polyphonic' analysis. According to Sigwart (1904 : 150ff), Bergson (1907 : 311ff) and many others, to negate is, fundamentally, to reject a positive proposition or, rather, an actual or potential assertion of the proposition one denies. A negative utterance therefore automatically evokes the positive assertion which it rejects. 
This type of analysis is often criticized on the grounds that it confuses propositional negation and the speech act of denial. Propositional negation makes propositions out of propositions. Both the input proposition $(p)$ and the output proposition (not $p$ ) can be asserted or denied, where 'assertion' and 'denial' are speech acts with propositional content (Table 3).

\begin{tabular}{|l|c|c|}
\hline & $\begin{array}{c}\text { Speech act of } \\
\text { assertion }\end{array}$ & Speech act of denial \\
\hline Positive proposition & Assertion that $p$ & Denial that $p$ \\
\hline Negative proposition & Assertion that not-p & Denial that $n o t-p$ \\
& & \\
\hline
\end{tabular}

Table 3 : Propositional negation and denial

As speech acts, denials have the same propositional content as the assertion they react to : one denies that $p$ by rejecting the assertion that $p$. The speech act of denying that $p$ is therefore distinct from the speech act of asserting that not- $p$; for these speech acts have different contents (the proposition that $p$ for the former, the proposition that not- $p$ for the latter).

Not everybody accepts these distinctions, however. Going to the opposite end of the spectrum, Frege sought to dispense with the speech act of denial altogether. In 'Negation', the third of his Logical Investigations, he reduces the act of denying a proposition to the act of asserting the negation of that proposition (Table 4). He therefore rejects the distinction between propositional negation and denial summarized in Table 3.

\begin{tabular}{|c|c|}
\hline Propositional content & Speech act \\
\hline Positive proposition & Assertion that $p$ \\
\hline Negative proposition & Assertion that not $p=$ denial that $p$ \\
\hline
\end{tabular}

Table 4 : Frege on negation and denial

A few years before Frege's 'Verneinung' was published, Reinach had pointed out that, as a matter of empirical fact, there are two sorts of negative judgment. Reinach rests his case on the following type of example : 
Let us consider the judgment, 'the king was not energetic', as it occurs in two different contexts. In the first context it is uttered by a historian who is expressing his opposition to the view that the king has been energetic. In the second context it occurs purely descriptively, in the course of a historical narrative. One must not overlook the quite different aspects which are possessed by the judgment in these two cases: in the first case it has the aspect of opposition to the contradictory positive judgment, ('the king was not energetic'), in the second case that of simple portrayal ('in this period the country flourished anew. The king was, be it said, not energetic, but ... '). (Reinach $1911: 356)$

Reinach calls the first type of negation (that which evokes the assertion which is being rejected) 'polemical' negation, and the second type 'simple' negation. ${ }^{26}$ He suggests that polemical negation is, or can be, marked by laying emphasis or, as it is now called, contrastive stress on the negative word : 'The king was not energetic'. Emphasis introduces a contrast between the negative proposition (which for Reinach as for Frege is the content of the negative judgment, whether the negation is polemical or simple) and the alternative which it discards, namely the positive proposition. As Reinach puts it,

All judgments carrying emphasis presuppose the existence of something against which this emphasis is directed. Emphasised negation, in particular, is necessarily directed against another contradictory judgment or sentence which is rejected by the judging subject. Thus the polemical negative judgment is distinguished in two respects from the simple negative judgment : it presupposes some contradictory positive judgment (or a contradictory positive sentence), against which the polemically judging subject is directed and which he rejects; and - connected closely with this - it is such that an emphasis is built into the execution of its negating function, through which the negative character of the state of affairs is set into relief relative to that opposing positive judgment. The rejection is directed against the alien judgment, the emphasis relates to the negative state of affairs posited by the subject himself (Reinach 1911 : 363-64)

\footnotetext{
${ }^{26}$ There is a third type of negation in Reinach's catalogue : 'retraction' negation, as in 'Not X but $Y^{\prime}$.
} 
To sum up, Reinach does not accept the view summarized in Table 3, for even in a case of denial, he thinks the propositional content of a negative utterance is a negative proposition. In this he anticipates Frege's position. But he acknowledges an important distinction between two kinds of negative utterance, depending on whether it reacts to (and presupposes) the corresponding positive assertion (Table 5).

\begin{tabular}{|c|c|c|c|}
\hline $\begin{array}{c}\text { Simple negative } \\
\text { judgment }\end{array}$ & $\begin{array}{c}\text { Propositional } \\
\text { content }\end{array}$ & force & presupposition \\
\hline $\begin{array}{c}\text { Polemical } \\
\text { (contrastive) } \\
\text { negative judgment }\end{array}$ & not $p$ & Assertion & Assertion \\
= denial & $\begin{array}{l}\text { Judgment directed } \\
\text { against another, } \\
\text { contradictory } \\
\text { judgment } p \text { rejected } \\
\text { by the judging } \\
\text { subject }\end{array}$ \\
\hline
\end{tabular}

Table 5 : Reinach on the two types of negative judgment

Perhaps inspired by Reinach, Ducrot, the relentless advocate of polyphony, also distinguishes between 'polemical negation' and what he calls 'descriptive negation' (Ducrot 1972 : 37-39 ; 1973: 123-31; Ducrot 1980b : 49-55). But he significantly complicates the picture, first by distinguishing between two types of polemical negation (polemical negation proper, and metalinguistic negation), ${ }^{27}$ and second, by showing that even what Reinach calls the 'simple negative judgment' (i.e. descriptive negation) requires a polyphonic analysis (Ducrot 1980b : 52-55). ${ }^{28}$ Even if a negative utterance 'not $p$ ' is a simple negative judgment

${ }^{27}$ Ducrot 1984 : 217-18. The difference between polemical and metalinguistic negation does not matter for our purposes : in both cases the assertion which is being rejected is evoked, and a polyphonic analysis is in order (since the enunciator of the denial must be different from the enunciator of what is denied). The notion of metalinguistic negation has been further elaborated by Larry Horn (see e.g. Horn 1985, 1989 : chapter 6), who initially got it from Ducrot.

${ }^{28}$ Ducrot is not totally clear, or consistent, on this matter since he sometimes seems to hold that any negation amenable to a polyphonic analysis counts as polemical rather than descriptive (Ducrot 1984 : 217-218). But I take Ducrot's 'on the contrary' test to show that 
by Reinach's lights, it is always possible to continue the discourse with 'on the contrary, $q$ ', where $q$ is contrary to the proposition that $p$ (and not to the negative proposition not $p$ which, according to Frege and Reinach, is the content of the utterance). For instance, we could elaborate on Reinach's example of simple negation as follows :

In this period the country flourished anew. To be sure, the king was not energetic ; on he contrary, he was of the lethargic type. But the economy...

'On the contrary' anaphorically picks up the proposition which is negated (that the King was energetic). But how is that proposition made available for pick up ? It is characteristic of simple/descriptive negation that the corresponding assertion has not been made or evoked before the negative utterance, which does not react to a previous statement (as polemical negation does). It must therefore be the negative utterance itself which evokes the positive proposition which 'on the contrary' anaphorically picks up. This supports Ducrot's claim that 'every negative utterance can be seen as a crystalized dialogue' (Ducrot 1980b : 50), a dialogue between someone who asserts that $p$ and someone (the speaker) who asserts that not $p$.

Of course, one might claim that the positive proposition is available for anaphoric pick-up simply because the negative proposition is constructed out of it, by applying the negation operator. But in the current framework, inspired by Hanks, the proposition to which the operator applies is intrinsically assertive. Its force is cancelled in negation contexts, and that can be analysed as a divergence between the context in which the negative utterance 'not $p^{\prime}$ is made and the illocutionary context projected by the embedded assertion that $p$.

On this view, there still is a difference between polemical negation and descriptive negation, even though both are given a polyphonic analysis. Polemical negation presupposes that the rejected assertion has been made or made salient, or that the rejected point of view has been expressed or evoked, prior to the utterance. Descriptive negation has no such presupposition. Still, Ducrot's 'on the contrary' test is meant to show that even a simple negative utterance without contrastive presuppositions evokes the corresponding assertion, and thereby projects an illocutionary context for that assertion.

even if a negative utterance does not exhibit 'opposition to the contradictory positive judgment' (an opposition which can be indicated by using contrastive stress), still it somehow evokes the positive proposition. 
At this point, a familiar problem arises when we try to specify e.g. who the enunciator of the prejacent is. In cases of polemical negation, we know who the enunciator is : it is the person whose positive assertion the negative utterance reacts to. But in cases of descriptive negation, it is hard to avoid appealing to a merely generic enunciator, because there is no particular assertion that the speaker is reacting to. The situation with descriptive negation is very similar to the situation with disjunction : in both cases, the polyphonic theory of force cancellation (as we may call it) only applies if we appeal to generic contexts. [Again, there is something stipulative about this move (appealing to generic contexts), but it is the best we can do if we want a unified theory of force cancellation. ${ }^{29}$ ]

\section{Appendix : Force cancellation beyond language}

In the paper I follow Hanks and couch my discussion in linguistic terms (assertion, illocutionary acts, etc.). But is that legitimate ? The problem of the unity of the proposition is not confined to cases in which speech acts with propositional content are performed using language. The phenomenon characterizes thought as well as language. Now if the phenomenon in question is not linguistic, then references to speech act theory are out of place. I heard that objection a couple of times, so I think something should be said about it.

${ }^{29}$ A weaker variant of the theory [[If one is unhappy with generic contexts, one can shift to a weaker, diachronic version of the theory. The weak variant gives up the idea that there is a unified theory of force cancellation. It]] distinguishes two [heterogeneous] types of force cancellation - force cancellation due to simulation, and force cancellation due to embedding - without trying to reduce one to the other via the appeal to generic contexts, but establishes a link between them in diachrony. Thus Ducrot suggests that descriptive negation descends (via 'delocutive derivation') from polemical negation (Ducrot 1984 : 218). The weak theorist can generalize this idea and distinguish three steps in the evolution of forcecancelling embedding. First step : the phenomenon of force cancelling simulation (perspective shifting) exists independent of embedding. Second step : The phenomenon occurs in embedding contexts (as it does in conditionals or polemical negation). Third step : the force cancelling character of embedding contexts becomes a matter of convention, as in Hanks's framework. Embedding cancels force even in the absence of simulation (as in the sort of case for which the stronger polyphonic theory appeals to generic contexts). 
It is true, of course, that the problem of the unity of the proposition arises not merely with respect to cases in which language is used, but also with respect to cases in which language is not used. But why should that be a difficulty ? On the sort of view developed by Hanks (and defended by me in the paper), what unifies the propositional content is what we may refer to abstractly as a committal act (or attitude) which may be either an illocutionary act [of assertion] in the linguistic case, or a mental act/attitude [of judgment or belief] in the nonlinguistic case. The theory is exactly the same in both cases, so the extension to the mental realm is entirely unproblematic. Whenever there is a committal act or attitude with propositional content, what unifies the content is the committal act or attitude, according to Hanks's theory. Linguistic acts of assertion are only a special case.

But we should distinguish the problem of the unity of the proposition, to which Hanks provides a solution, and the problem offorce cancellation, which arises for Hanks's account and to which I provide a solution. My solution to the problem of force cancellation crucially appeals to the notion of a locutionary act, analysed as the act of conventionally indicating the performance of a given illocutionary act. Now, the notion of an illocutionary act can be subsumed under the more general notion of a committal act (an act which can be indifferently mental or linguistic), but the notion of a locutionary act, as I analyse it, seems to be fundamentally linguistic and related to the existence of conventional forms for performing illocutionary acts. So, with respect to the problem of force cancellation, the objection makes sense: if the phenomenon (force cancellation) is not linguistic, then references to the theory of locutionary acts are out of place.

Let us first deal with the issue, whether and to what extent force cancellation might be a linguistic phenomenon. As we have seen, force cancellation occurs in two types of case : cases of displayed speech or thought, such as irony or free indirect speech, and cases in which a complex propositional content is built up with the help of logical connectives ('compound thoughts', to use Frege's terminology). Now many philosophers hold that compound thoughts are made possible by language, and are therefore unavailable to nonlinguistic creatures. If that is the case, then there is no immediate objection to analysing that type of force cancellation with the help of linguistic notions. ${ }^{30}$

\footnotetext{
${ }^{30}$ That the phenomenon may occur in inner as well as outer speech is evidently not a problem for the analysis. Silent thought is still thought informed by language, in contrast to animal thought — thought available to nonlinguistic creatures.
} 
Other philosophers think there can be (proto-)conditionals or (proto-)negation in animal thought, however. How, then, can a 'linguistic' account of force cancellation such as that I have offered be made compatible with the putative existence of the phenomenon in animal thought? I respond that my account is not particularly linguistic, appearances notwithstanding. I have argued that the type of force-cancellation at work in embedding cases should be understood in the light of the other type of force cancellation - the type which involves simulation and role-playing, as in e.g. irony or free indirect speech. Now roleplaying is tied to theory of mind abilities and is found early in children in the form of pretense games. These games are precocious manifestations of the ability to engage into fiction (Walton 1990), an ability which, according to Clark (2016), also underlies the use of gestures and bodily expressions in oral communication. The relevant cognitive abilities (simulation/pretense, role-playing, etc.) do not seem to be specifically linguistic. We should acknowledge the possibility for a nonlinguistic creature with a rich theory of mind (assuming there can be nonlinguistic creatures with a rich theory of mind) to gesturally express an attitude while overtly conveying that one does not have the attitude. This can be accounted for using basically the same tools I have suggested : we can define the context of an attitude just as we define the context of an illocutionary act, and we can substitute the context of expression for the context of the locutionary act.

I conclude that if there is, in animal thought, a proto-analog of the sort of logical compounding we find in linguistic thought, there is no reason why there couldn't be also a simulation-based analog of the force-cancellation mechanism I described for linguistic thought. There is nothing specifically linguistic about that mechanism, on my account. ${ }^{31}$

\footnotetext{
${ }^{31}$ We can perhaps go further. The assumption that simulation mechanisms are independent of language and work in tandem with embedding suggests that a closer link may tie the two phenomena (syntactic embedding and force-cancelling simulation) : the phenomenon of embedding itself may have phylogenetically developed from the interplay between the protolinguistic faculty (before the emergence of what Cosmides and Tooby 2000 refer to as 'scope syntax') and the 'perspective shifting' faculty, which crucially involves the phenomenon Clark has dubbed 'layering' (Clark 1996 ; see also Sperber's analogous remarks on the human capacity for 'metarepresentation'). This type of account is interesting because it reverses the order of explanation with respect to theories which give a central role to the complex structures of language in the development of theory of mind abilities (see e.g. de
} Villiers 2005, 2007). 


\section{References}

Anscombre, J.C. and Ducrot, O. (1977) Deux mais en français? Lingua 43: 23-40.

Austin, J.L. (1975) How to Do Things with Words. Oxford : Clarendon Press.

Barker, S. (2004) Renewing Meaning. Oxford : Oxford University Press.

Bergson, H. (1907) L'Evolution Créatrice. Paris : Alcan.

Clark, H. (1996) Using Language. Cambridge : Cambridge University Press.

Clark, H. (2016) Depicting as a Method of Communication. Psychological Review 123 : 32447.

Clark, H. and Gerrig, R. (1984) On the Pretense Theory of Irony. Journal of Experimental Psychology: General 113 : 121-26.

Collins, J. (2011) The Unity of Linguistic Meaning. Oxford : Oxford University Press.

Cornulier, B. de (1985) Effets de Sens. Paris : Editions de Minuit.

Cosmides, L. and Tooby, J. (2000) Consider the Source : The Evolution of Adaptations for

Decoupling and Metarepresentation. In D. Sperber (Ed.), Metarepresentations: A

multidisciplinary perspective, 53-115. New York: Oxford University Press.

Davies, M. and Stone, T. (eds.) (1995) Mental Simulation. Oxford : Blackwell.

De Brabanter, P. (ed.) (2005) Hybrid Quotation. Amsterdam : John Benjamins (= Belgian Journal of Linguistics 17, 2003).

De Villiers, J. (2005) Can Language Acquisition Give Children a Point of View? In

Astington, J. and Baird, J. (eds.) Why Language Matters for Theory of Mind, 186-219. New York : Oxford University Press.

De Villiers, J. (2007) The Interface between Language and Theory of Mind. Lingua 117 : 1858-78.

Doron, E. (1991) Point of View as a Factor of Content. In S. Moore and A. Wynner (eds.)

Proceedings of the First Semantics and Linguistic Theory Conference (SALT 1), 51-64.

Ithaca, NY: Cornell University Press.

Ducrot, O. (1972) Dire et ne pas dire. Paris : Hermann.

Ducrot, O. (1973) La Preuve et le Dire: Langage et Logique. Paris: Mame.

Ducrot, O. (1980a) Analyses pragmatiques. Communications 32 : 11-60.

Ducrot, O. (1980b) Analyse de texte et linguistique de l'énonciation. In O. Ducrot et al. Les Mots du discours, 7-56. Paris : Editions de Minuit. 
Ducrot, O. (1984) Esquisse d'une théorie polyphonique de l'énonciation. In O. Ducrot Le Dire et le Dit, 171-233. Paris : Editions de Minuit.

Dummett, M. (1973) Frege : Philosophy of Language. London : Duckworth.

Eckhart, R. (2015) The Semantics of Free Indirect Discourse. How Texts Allow us to MindRead and Eavesdrop. Leiden: Brill.

Fauconnier, G. (1985) Mental Spaces. Cambridge, Mass : MIT Press/Bradford Books.

Fodor, J. (1983) The Modularity of Mind. Cambridge, Mass : MIT Press.

Frege, G. (1918-26) Logical Investigations. Eng. trans. in B. McGuinness (ed.) Collected Papers on Mathematics, Logic, and Philosophy, 351-406. Oxford: Blackwell, 1984.

Gaskin, R. (2008) The Unity of the Proposition. Oxford : Oxford University Press.

Geach, P. (1960). Ascriptivism. Reprinted in Geach (1972), 250-54.

Geach, P. (1965) Assertion. Reprinted in Geach (1972), 254-69.

Geach, P. (1971) Mental Acts. $2^{\text {nd }}$ ed. London : Routledge \& Kegan Paul.

Geach, P. (1972) Logic Matters. Oxford : Blackwell.

Gibson, M. (2004) From Naming to Saying : the Unity of the Proposition. Oxford :

Blackwell.

Grice, H.P. (1989) Studies in the Way of Words. Cambridge, MA : Harvard University Press.

Hanks, P. (2007) The Content-Force Distinction. Philosophical Studies 134:141-164.

Hanks, P. (2011) Structured Propositions as Types. Mind 120 : 11-52.

Hanks, P. (2015) Propositional Content. Oxford : Oxford University Press.

Hare, R.M. (1950) Practical Reason. Unpublished dissertation, University of Oxford.

Hare, R.M. (1970) Meaning and Speech Acts. Reprinted in Hare (1971), 74-93.

Hare, R.M. (1971) Practical Inferences. London : MacMillan.

Hom, C. and Schwartz, J. (2013) Unity and the Frege-Geach Problem. Philosophical Studies $163: 15-24$.

Horn, L. (1985) Metalinguistic Negation and Pragmatic Ambiguity. Language 61: 121-74.

Horn, L. (1989) A Natural History of Negation. Chicago: The University of Chicago Press.

Husserl, E. (1900-1901) Logische Untersuchungen. Halle : Newmeyer.

King, J. (2007) The Nature and Structure of Content. Oxford : Oxford University Press.

King, J., Soames, S. and Speaks, J. (2014) New Thinking About Propositions. Oxford: Oxford University Press.

Lapointe, S. (ed.) (2015) Themes from Ontology, Mind, and Logic. Essays in Honour of Peter Simons. Leiden : Brill/Rodopi. 
Leslie, A. (1987) Pretense and Representation: The Origins of "Theory of Mind."

Psychological Review 94 : 412-426.

Meinong, A. (1902) Ueber Annahmen. Leipzig : Barth.

Mulligan, K. (2015) Annehmen, Phantasieren und Entertaining. Husserl and Meinong. In S. Lapointe (ed.) (2015), 245-83.

Quine, W.v.O. (1960) Word and Object. Cambridge : Harvard University Press.

Recanati, F. (1980) Explicit Performatives, Speech Acts, Locutionary Meaning and Truth-

Value. In M. Bierwisch, F. Kiefer and J. Searle (eds.) Speech Act Theory and Pragmatics, 205-20. Dordrecht : Reidel.

Recanati, F. (1987) Meaning and Force. Cambridge : Cambridge University Press (Eng. trans. of Les Enoncés Performatifs, Paris : Minuit, 1981).

Recanati, F. (2000) Oratio Obliqua, Oratio Recta. Cambridge, MA : MIT Press/Bradford Books.

Recanati, F. (2004) Literal Meaning. Cambridge : Cambridge University Press.

Recanati, F. (2007) Indexicality, Context, and Pretense: A Speech-Act Theoretic Account. In N. Burton-Roberts, Pragmatics, 213-229. London : Palgrave-Macmillan.

Recanati, F. (2010) Truth-Conditional Pragmatics. Oxford : Oxford University Press.

Recanati, F. (2013) Content, Mood, and Force. Philosophy Compass 8 : 622-32.

Reiland, I. (2013) Propositional Attitudes and Mental Acts. Thought 1: 239-45.

Reichenbach, H. (1947) Elements of Symbolic Logic. London : Macmillan.

Reinach, A. (1911) Zur Theorie des Negativen Urteils. In A. Pfänder (ed.) Festschrift für Theodor Lipps, 196-254. Leipzig: J. A. Barth. Translated as 'On the Theory of Negative Judgement' in B. Smith ed. (1982), 315-77.

Russell, B. (1903) Principles of Mathematics. Cambridge : Cambridge University Press.

Schlenker, P. (2004) Context of Thought and Context of Utterance : A Note on Free Indirect Speech and the Historical Present. Mind and Language 19 : 279-304.

Searle, J. (1968) Austin on Locutionary and Illocutionary Acts. Philosophical Review 77: 405-24.

Searle, J. (1969) Speech Acts. Cambridge : Cambridge University Press.

Sharvit, Y. (2008) The Puzzle of Free Indirect Discourse. Linguistics and Philosophy 31: 35395.

Sigwart, C. (1904) Logik, 3rd ed. Tübingen: Mohr.

Smith, B. (ed.) (1982) Parts and Moments. Studies in Logic and Formal Ontology. Munich:

Philosophia Verlag. 
Soames, S. (2010) What is Meaning ? Princeton : Princeton University Press.

Soames, S. (2012) Propositions. In D. Fara and G. Russell (eds.) Companion to the

Philosophy of Language, 209-220. London : Routledge.

Soames, S. (2014a) Cognitive Propositions. In King, J., Soames, S. and Speaks, 91-124.

Soames, S. (2014b) Clarifying and Improving the Cognitive Theory. In King, J., Soames, S. and Speaks, 226-44.

Soames, S. (2015) Rethinking Language, Mind, and Meaning. Princeton : Princeton

University Press.

Sperber, D. metarepresentation in an evolutionary perspective

Sperber, D. and Wilson, D. (1981) Irony and the Use/Mention Distinction. In P. Cole (ed.)

Radical Pragmatics, 295-318. London : Academic Press.

Sperber, D. and Wilson, D. (1986) Relevance. Oxford : Blackwell.

Stokke, A. (2013) Protagonist Projection. Mind and Language 28 : 204-32.

Walton, K. (1990) Mimesis as Make-Believe. Cambridge : Harvard University Press.

Whiten, A. and Byrne, R. (1997) Machiavellian Intelligence II : Extensions and Evaluations.

Cambridge: Cambridge University Press.

Wilson, D. (2000) Metarepresentation in Linguistic Communication. In D. Sperber (ed.)

Metarepresentation : a Multidisciplinary Perspective, 441-48. Oxford : Oxford University

Press.

Wilson, D. (2006) The Pragmatics of Verbal Irony : Echo or Pretence ? Lingua 116 : 1722-43.

Wilson, D. and Sperber, D. (1992) On Verbal Irony. Lingua 87 : 53-76.

Wilson, D. and Sperber, D. (2012) Meaning and Relevance. Cambridge : Cambridge University Press. 